\title{
For an Effective Management of the Functional Capacities of Companies: A Study of Pharmaceutical Companies
}

\author{
Saker Besma ${ }^{*}$, Chaib Rachid, Kahlouche Abdelaziz \\ Laboratory of Transportation Engineering and Environment, University Frères Mentouri Constantine 1, Constantine 2500, \\ Algeria
}

Corresponding Author Email: besma.saker@student.umc.edu.dz

https://doi.org/10.18280/ijsse.110507

Received: 7 June 2021

Accepted: 26 September 2021

\section{Keywords:}

supply chain, logistics, risk, competition, continuous improvement, pharmaceutical sector

\begin{abstract}
The development of industry, continuous innovation and shortening production times and demands from customers to deliver products in the right quantities, at the right time, at the right price and with better quality have led to increased competitive pressures. These visions have created risks and disruptions in the supply chain. This could compromise the achievement of the targeted objectives as well as the continuity of the operating cycle, or even the sustainability of the company. Consequently, it is recommended to identify, upstream, any incident having an impact on the company's functional capacities. It is only by controlling these risks that manufacturers can guarantee the smooth running of their logistics activities, the objective of this work. This work is clearly based on the identification and evaluation of risks in an emerging economy through a qualitative approach based on interviews and a questionnaire with purchasing and distribution managers. The results displayed allow managers to refocus on the priorities to be solved in order to design viable and livable organizations, or even to act effectively to correct the errors that have been revealed or to continue and increase its development. As a case study we chose the pharmaceutical sector in the Constantine region. This is the first time this type of study has been done in Algeria.
\end{abstract}

\section{INTRODUCTION}

The development of industry, continuous innovation and shortening production times and demands from customers to deliver products in the right quantities, at the right time and with better quality have led to increase the supply chain's exposure to risk and competitive pressures. These elements are now a growing part of the aspects that consumers take into account when purchasing. Beyond these aspects, companies need to have a better understanding of the impacts of their products throughout their life cycles. The supply chain appears to encompass all the processes and flows that connect it to suppliers and customers on both sides [1]. Thus the multiplication of activities and actors creates risks and disruptions within the supply chain, these risks can jeopardize the achievement of objectives and also the continuity of the operating cycle, and even the company's sustainability. It is important to remember that the concept of supply chain risk refers to unexpected events that can negatively affect the flow of information and the achievement of business objectives and can come from a single source or multiple sources in the supply chain [2]. As a result, a thorough knowledge of the risks makes it possible to better assess the potential consequences of the phenomena and to put in place appropriate preventive or protection measures [3]. Consequently, it is recommended to identify any incident, any work stoppage, and any alteration having an impact on the functional capacities of the company upstream. Thus, every company must be efficient in its way of operating $[4,5]$ in order to maintain a competitive advantage. Only by identifying and evaluating the risks associated with their supply and distribution networks can manufacturers guarantee the smooth running of their logistics activities, which is the objective of our study.

The supply chain risk factors that companies face can be classified in different ways and as mentioned in the literature, we have adopted a classification in 4 families inspired by Refs. [6-9] namely: supply risks, process risks, demand risks and environmental risks, detailed in the following:

In order to measure the supply risk factors, five components were used, Refs. [10, 11] namely: Supplier failure, Supplier quality problems, Increase in the price of raw materials, Late delivery of raw materials, Inability of suppliers to respond to quantitative variation.

The risk factors associated with the process were assessed using five components based on Refs. [9, 12, 13]: Machine breakdown, Information systems failure, Labour dispute, Work accident, and Limited production capacity.

With regard to demand risk factors, four elements were used, inspired by Refs. [14, 15]: Unexpected fluctuations in demand, Inventory shortage, Disruption of delivery times, Product failure.

Finally, environmental risk factors were measured through four components, inspired by Refs. [16, 17]: Exchange rate fluctuations, Regulatory issues, Natural disasters, Pandemics.

From now on, adapting to the effects of changing behaviour and attitudes in Algerian companies has become a necessity and an unavoidable step in order to preserve the security of its supply chain, the maintenance of jobs and the sustainability of companies, both for the current generation and for future generations. Sustainability symbolizes the very purpose of 
management and administration, even to encourage timely decision-making in the market and to engage in a process of continuous improvement [18].

\section{METHODOLOGY}

This article describes the development of a continuous improvement approach to supply chain practices based on the participation of all interdependent actors and operators, particularly those directly involved in the activity. In order to enhance performance and guaranteeing the sustainability of companies, we used this approach. Moreover, the quality of the information and data collected on the system is obtained in several ways, qualitative, semi-quantitative or quantitative [19, 20].

In this work, we have chosen to focus on a qualitative approach guided by real data from the field. The working method envisaged is based on the interview and the feedback, an a posteriori approach, of the undesirable events manifested in the company on the one hand. This approach is above all a learning tool for organizations, which allows them to build up a risk memory. The aim of this rapidly expanding tool is to provide the means to reflect on the experience acquired during accidents and/or incidents that occurred in normal or disorganized situations, to draw the consequences, to memorize them and to reuse them. On the other hand, once the risk factors have been determined, the use of the questionnaire to allow us to determine the weight of each risk factor on the functioning of the organization. The proposed work environment assessment model consists of the following steps (Figure 1).

-Semi-structured interviews to collect data and understand the operating principle of these companies, and the risks related to their supply and distribution networks. This operation lasted more than two months, the interviewees of this research are purchasing, operation and distribution managers whose working time in the company exceeds 6 years, the data and information collected are therefore reliable. The questions asked to the participants are about risk factors related to supply, operations, demand and environment. In addition, we used in this research the information collected from the companies' historical data through annual reports for production volume, sales and supplier performance;

-Evaluation of the work environment and identification of weak points and sources of alterations in the supply chain in each company using a questionnaire addressed to all managers working in this sector of companies. Once the risk factors have been determined, the use of the questionnaire allowed us to determine the weight of each risk factor on the functioning of the organization. The questionnaire consists of four categories of risk factors associated with the supply chain where we used a five-point Likert scale to measure both the likelihood and the impact of each risk factor, processing the results of the questionnaire with the software SPSS;

-Proposal of improvement actions to adjust the strategy, correct errors that have been revealed and refocus on the priority actions to be taken. It is a process during which the manager observes with his own eyes the mapping of the working conditions for a well-defined period and thus makes decisions based on real information. It must be a source of progress and continuous improvement in the face of concrete realities. The quality of this analysis is fundamentally based on the information that the safety department will be able to collect in the field, thus avoiding the recurrence of accidents and incidents that have occurred in the entity and proposing solutions to the deficiencies observed.

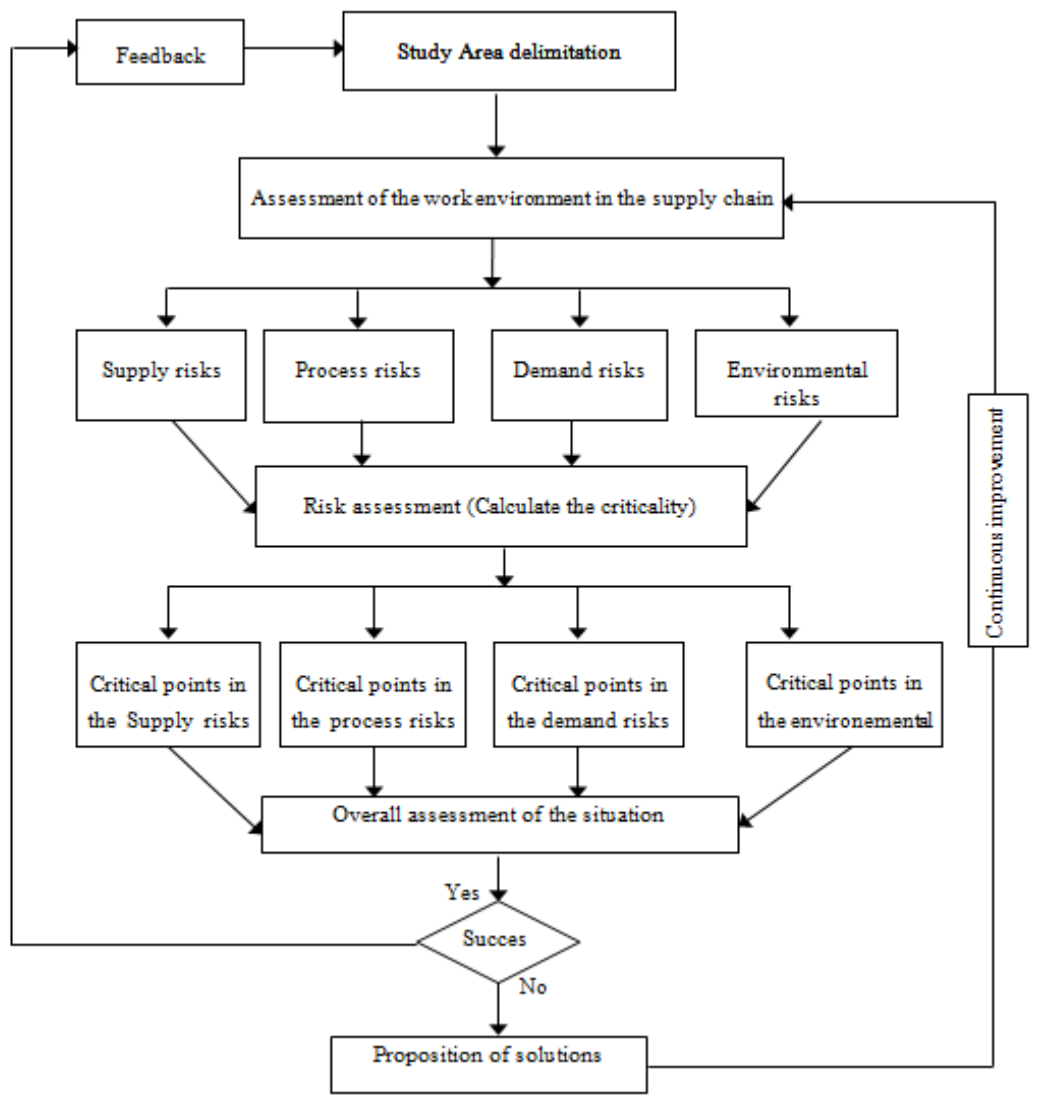

Figure 1. Work methodology envisaged 
As a case study we have chosen the pharmaceutical sector in the region of Constantine. This is the first time that this type of study has been carried out in Algeria. This choice is due to several factors:

Firstly, this region has become a pharmaceutical hub par excellence because it includes a large number of companies where evaluation studies on pharmaceutical manufacturers are almost absent, despite the fact that these companies are faced with many risks.

Secondly, the occurrence of any risk in the pharmaceutical industry could affect the availability of drugs on the market, which threatens the lives of patients.

The number of companies contacted for the study was 23 . Of these, $73 \%$ responded positively to our study.

\section{RISK IDENTIFICATION AND ASSESSMENT}

According to Manuj and Mentzer, "Risk is equal to the probability of a loss multiplied by the impact of that loss" [14]. Risk assessment is a thorough inspection of the workplace to identify elements, situations and processes that can cause harm to the smooth running of the organisation. Consequently, it is essential to know the safety system that best contributes to the safe operation of installations, processes and procedures. Once the risk has been identified, the probability and seriousness of the risk is analysed and evaluated in order to identify those that need to be treated urgently on the basis of defined criteria. The next step is to determine what measures to take to prevent the harm from occurring. The rating scale used in this work is the five-point Likert-type scales [15, 21], where we asked respondents to indicate in the questionnaire the degree of probability of the risk occurring from (unlikely to frequent), Table 1 and the degree of its impact from (minor to major), Table 2.

We calculated the average values for both probability of occurrence (Pi) and impact (Gi) for each risk factor, based on these two indicators, the level criticality $(\mathrm{Ci})$ is determined using the following equation proposed by Dani [22].

$$
\mathrm{Ci}=\mathrm{Pi} \times \mathrm{Gi}
$$

Table 3 shows the average, of both the probability of occurrence, the degree of gravity and the Criticality for each risk factor in the four categories associated with the supply chain.

In order to carry out our analysis and to identify the priorities of the operations to be undertaken, and after in-depth study with the purchasing, operations and distribution managers, and with reference to the annual reports and risk assessment files and matrices a criticality scoring grid was proposed (Figure 2). It is useful to know the status of the risks before handling. We also used the radar diagram for a clear reading of the results.

Table 1. Degrees of probability

\begin{tabular}{|c|c|c|c|c|c|}
\hline Degree & 1 & 2 & 3 & 4 & 5 \\
\hline Probability & Unlikely & Rarely & Occasion & Likel & Frequent \\
\hline
\end{tabular}

Table 2. Degrees of gravity

\begin{tabular}{cccccc}
\hline Degree & 1 & 2 & 3 & 4 & 5 \\
\hline \multirow{2}{*}{ Gravity } & $\begin{array}{c}\text { Minor } \\
\text { gravity }\end{array}$ & $\begin{array}{c}\text { Low } \\
\text { gravity }\end{array}$ & $\begin{array}{c}\text { Medium } \\
\text { gravity }\end{array}$ & $\begin{array}{c}\text { Strong } \\
\text { gravity }\end{array}$ & $\begin{array}{c}\text { Major } \\
\text { gravity }\end{array}$ \\
\hline
\end{tabular}

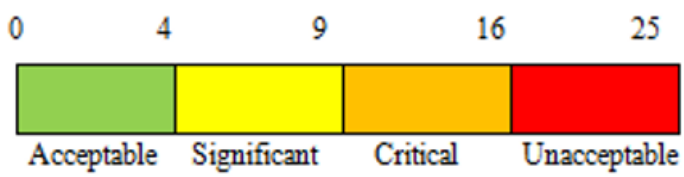

Figure 2. Proposed criticality rating grid

Table 3. Probability, gravity and criticality values of the each risk factor

\begin{tabular}{ccccc}
\hline & Risk factor & Probability & Gravity & Criticality \\
\hline \multirow{4}{*}{ Supply risks } & Supplier failure & 2.29 & 4.29 & 9.82 \\
& Supplier quality problems & 1.82 & 4.52 & 8.22 \\
& Increase in the price of raw materials & 4.04 & 4.29 & 17.33 \\
& Late delivery of raw materials & 3.17 & 3.88 & 12.29 \\
& Inability of suppliers to respond to quantity variation & 2.05 & 3.41 & 6.99 \\
Process risks & Machine breakdown & 2.82 & 3.75 & 10.57 \\
& Failure of information systems & 2.47 & 3.94 & 9.73 \\
& Labour dispute & 1.94 & 1.58 & 3.06 \\
Demand Risk & Workplace accident & 2.05 & 3.04 & 6.23 \\
& Limited production capacity & 2.64 & 3.05 & 8.05 \\
& Unexpected fluctuations in demand & 3.81 & 4.35 & 16.57 \\
& Inventory shortage & 3 & 4.41 & 13.23 \\
Environmental risks & Disruption of delivery time & 2.88 & 3.47 & 9.99 \\
& Product failure & 1.44 & 4.83 & 6.95 \\
& Exchange rate fluctuations & 4.17 & 4.61 & 19.22 \\
& Regulatory problems & 2.82 & 3.00 & 8.46 \\
& Natural disasters & 1.17 & 4.82 & 5.63 \\
\hline
\end{tabular}

\section{RESULTS AND ANALYSIS}

\subsection{Supply risks}

The objective of the supply risk assessment is to build a strategy to mitigate and manage these risks. The supply risk management profession is the most important specialty in the supply chain domain; because it is a very important element that allows any company to ensure its functioning and guarantee its continuity, even its durability. The result is shown in Figure 3.

Observation: According to the results obtained and 
illustrated in Figure 3, it appears that the risk of an increase in the price of raw materials is the most dominant and is situated in the unacceptable zone with a critical value of 17.33. This negatively affects manufacturers and puts them in a difficult situation because the sale prices of medicines in Algeria are determined by the Ministry of Health. This situation requires an emergency action plan for the sustainability of the sector. The second risk is the late delivery of raw materials and the failure of the supplier who is in the critical zone. It should be noted here that the city of Constantine has become a pharmaceutical hub par excellence for its contribution to the creation of a national product to reduce the import of expensive medicines but the share of raw materials imported is increasing. In our opinion, the problem of delays in the delivery of raw materials is linked to the distance from the suppliers and the problems of customs clearance and the delays of containers stagnating at the ports, as most of the raw material is imported from other seas. As for the failure of the supplier, in our opinion, it may arise due to poor performance as well as due to force majeure and bankruptcy.

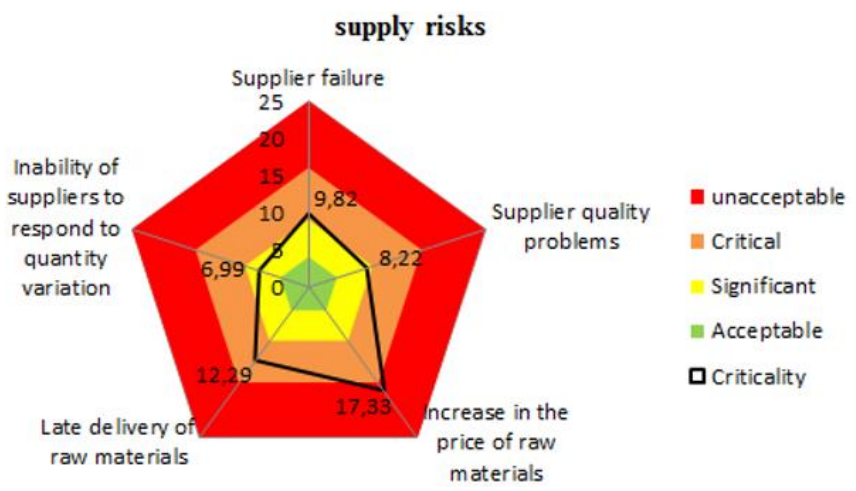

Figure 3. Representation of the supply risks assessment

Another problem that should not be overlooked is the problem of supplier quality and the inability of suppliers to respond to the quantitative variation in the significant area. However, in our view, this problem is related to the manufacturing processes and the availability of raw material.

\subsection{Process risks}

The purpose of assessing these risks is to know the extent of their impact on business performance. Cucchiella and Gastaldi defined Process risks is being the risk that a negative effect on the internal capacity of the company in the production and manufacturing processes [23]. Figure 4 shows the following results:

\section{Process Risks}

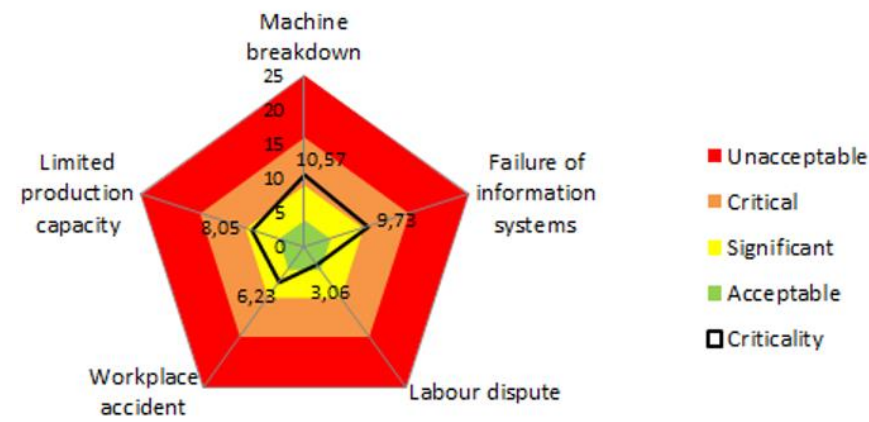

Figure 4. Representation of the process risks assessment
Observation: We note that the risks of machine breakdown and information system failure are the most dominant, located in the critical zone. Their severity is very important and generates crucial problems in companies. An information system failure can lead to supply delays, stock-out problems and quality problems, and even harm competition [24]. In our opinion, the reason for machine failure is due to poor maintenance, operator errors and material problem. On the other hand, we note that accidents and limited capacity are in a significant area. In our view, limited capacity is due to several factors, including the lack of capital to store raw materials, the instability of their prices and machine breakdowns. However, labour disputes are within an acceptable range, given that we are in a private sector!

\subsection{Demand risks}

It is considered a major risk in the supply chain. It requires a lot of attention for the proper functioning of the supply chain. The results of the survey are illustrated in Figure 5.

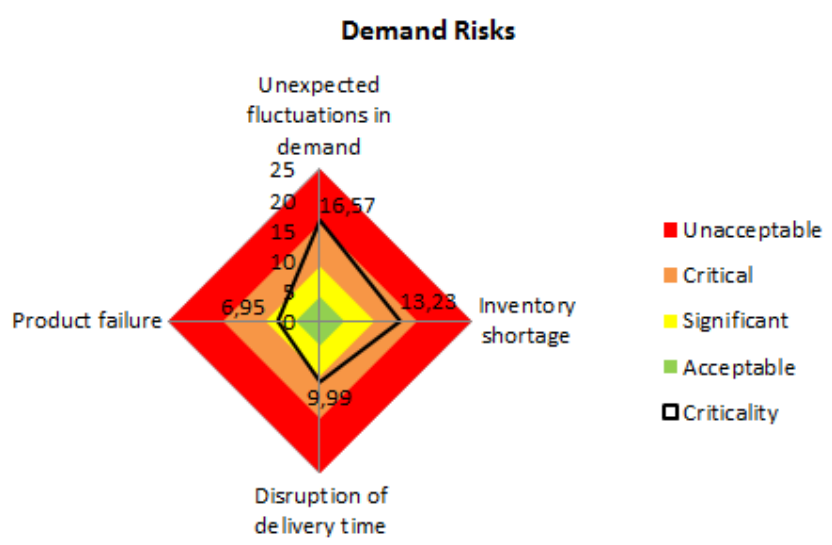

Figure 5. Representation of the demand risks assessment

Observation: The risk of unexpected fluctuations in demand is in the unacceptable zone, the red zone. This risk is due to a wrong estimation of what the customer will buy and when. This estimate is often wrong. As a result, demand is always uncertain [25]. In our view, there is a gap in marketing and pharmaceutical companies will need to put in place appropriate plans and strategies to address these risks. Some respondents explained that «the population growth and the state policy of free and reimbursable treatment of medicines from the Social Security party have led to higher drugs consumption». As a result the demand has become unstable. However, concerning the stock out and the disruption of delivery time are located in the critical area. Sorry, the shortage of medicines stock is not allowed as a vital product in the lives of citizens. In our view, the problem of delivery time disruption is closely related to the late delivery of raw materials and the availability and maintainability of production tools and regulatory issues. On the other hand, product failure is in the significant region, which indicates that additional efforts are needed to reduce this risk.

\subsection{Environmental risks}

There are, however, some risks that few companies take into account, often placing them at the bottom of their priority list. These are environmental risks. This class of risk is considered immature because of its unexpected occurrence. Thus, 
environmental risks are all the risks that the simple exercise of your activity (or, sometimes, certain occasional projects) can generate, producing a direct or indirect impact on the human and natural environment of the company. The consequences of a proven environmental risk can, above all, weaken the sustainability of companies. The objective of the assessment of these risks is to examine and study them in order to avoid the weakness of the supply chain. The results of our study are presented in Figure 6.

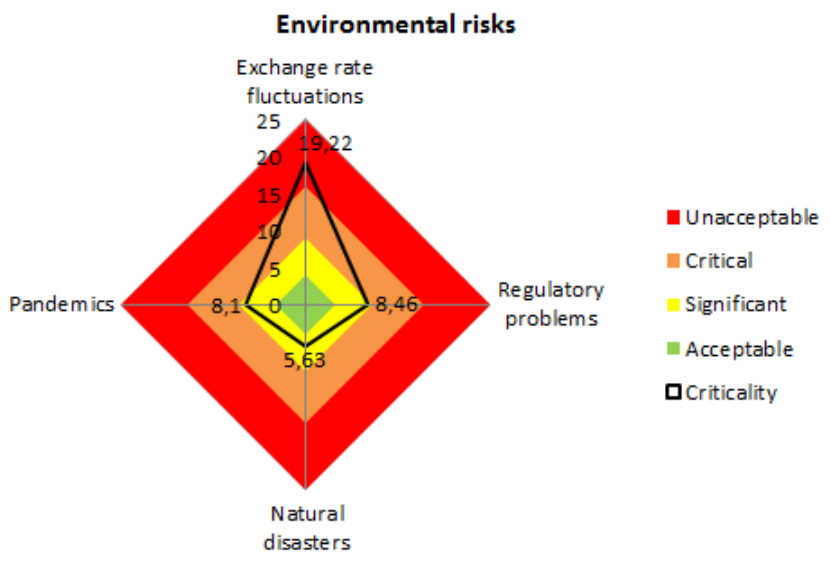

Figure 6. Representation of the environmental risks assessment

Observation: The results show us that the exchange rate fluctuation is located in the unacceptable zone with a very high criticality value of 19.22 . However, as most of the raw material is imported, this will influence and disrupt the market for medicines, even making prices unstable and weakening the sustainability of companies. On the other hand, natural disasters, epidemics and regulatory problems are in the significant area, these risks are considered as phenomena that cannot be controlled, so companies will have to pay more attention to these risks [26]. Nowadays, "environmental risks" tend to refer to all risks related to environmental damage, combining and making coherent the major risks with health and ecological risks.

\section{RECOMMENDATIONS AND RISK MITIGATION STRATEGY}

After identifying and assessing the risks associated with the pharmaceutical supply chain in the city of Constantine, we need to suggest strategies that are characterised by their role in mitigating the negative effects of risks [27]. It emerges from our study that there are nine predominant of risk from all types of supply chain risk, supply, demand, operations, and environment risks that exist in the two unacceptable and critical areas that are the most urgent risks and need to be mitigated as a priority, the discussion of this mitigation framework is presented in the following section:

\subsection{For supply risks}

Our analysis shows that the increase in the price of raw materials affects the production potential and disrupts the market, which weakens the sustainability of organisations, given that the selling price of medicines in Algeria is set by the Ministry of Health. Therefore, the ideal solution to mitigate this risk is to resort to a policy of signing long-term contracts [28] to maintain prices. We also suggest that those responsible for this sector persuade the Ministry of Health to review pricing to reflect the real costs of producers while ensuring the availability of medicines at reasonable prices. In the meantime, we suggest adapting a multi-source strategy (more redundant suppliers) as a redundant strategy to ensure continuous supply in the face of supplier failures [29]; it also reduces the impact of unexpected price increases [6]. Furthermore, through a case study Agigi et al. conducted on several companies showed that the use of multi-sourcing strategy allowed them to cope with supply chain disruptions [30]. On the other hand, there is another strategy to reduce the supply risks associated with late delivery of raw materials that can occur due to supplier machine breakdowns or long distance transport, as well as customs problems, which are represented in the increase inventory levels. Additional stock is often considered as a tool to mitigate supply risk. Ochieng has also shown [31] through his empirical research that redundancy (such as building up additional inventory) positively affects the performance of the supply chain and its continuity to function smoothly in the face of supply disruption.

\subsection{For process risks}

Here, the risks of machine breakdown and failure in information systems are classified as critical risks. Nowadays, a breakdown is a risk that becomes a reality. Despite the fact that companies are striving to achieve their goals and remain competitive thanks to modern technologies. However, due to the lack of training and skills of staff, unexpected events in the information system can lead to inefficient service for companies. Regarding failures in information systems, we suggest robust backup systems to minimize these risks [12]. On the other hand, regarding the risks of machine failure that negatively affect delivery times as well as product quality in case of errors, we suggest a competent maintenance service and regular staff training. This now includes prevention measures, monitoring, staff training.

\subsection{For demand risks}

Here, three risks have been identified, represented by unexpected fluctuation in demand, stock shortage and disruption of delivery times of finished products. In our view, these risks are closely linked to the availability of raw material and can only be mitigated by addressing the raw material problem. To reduce the impact of the fluctuation risk, we first suggest a strategy of increasing the inventory level. Additional stock reduces order lead times and thus increases customer satisfaction [32]. Also maintaining a safety stock with the necessary quantity gives the company a competitive advantage [25]. Through a study conducted by Darouich and Dhiba [33] in pharmaceutical companies in Morocco, it was revealed that additional stock helps to make final deliveries in a timely manner. In an attempt to overcome the impact of disrupted delivery times, companies need to re-plan orders through communication with members of the supply chain and by focusing on collaboration and information exchange to coordinate rapid response to order management [34-36]

\subsection{For environmental risks}

Environmental risks and their consequences can no longer 
be neglected by companies today. We must be very careful, as the consequences of a proven environmental risk can weaken the sustainability of companies. The practice of purchasing goods and services from external suppliers now exposes the supply chain to the risks of exchange rate fluctuations [37]. As most of the raw material is imported. In order to mitigate this risk, we first propose a strategy of creating financial hedges, whereby supply chains protect its businesses from a sudden change in foreign currencies that would reduce the impact of these risks $[10,38]$, when the foreign exchange risk is reduced, it supports the mitigation of the purchasing risk. Similarly, we suggest reducing reliance on external sources and working on producing and sourcing raw materials in Algeria instead of importing them.

\section{CONCLUSION}

The objective of this research is to identify and assess the nature of the risks present in the pharmaceutical supply chain and to create a strategic framework by prioritising several dimensions of supply chain risk. This research allowed us to identify the main risk factors in four categories of the supply chain: supply, process, demand and environment that negatively affect the chain. While we have identified and prioritised the weight of each risk, such research will indicate the critical risk factors that should remain of primary interest in the context of the pharmaceutical industry. This would allow the prioritisation of risk management and mitigation steps.

Finally, the results call on managers to refocus on priorities in order to design viable and livable organisations, or even to act effectively to correct errors that have been revealed or to continue and increase their development. Companies must look beyond their own site and consider the indirect impacts of their activity.

\section{REFERENCES}

[1] Kozarević, S., Puška, A. (2018). Use of fuzzy logic for measuring practices and performances of supply chain. Operations Research Perspectives, 5: 150-160. https://doi.org/10.1016/j.orp.2018.07.001

[2] Lavastre, O., Gunasekaran, A., Spalanzani, A. (2012). Supply chain risk management in French companies. Decision Support Systems, 52(4): 828-838. https://doi.org/10.1016/j.dss.2011.11.017

[3] Hassani, M., Chaib, R., Bouzerara, R. (2020). Vulnerability assessment for major industrial risks proposal for a semiquantitative analysis method (VAMIR) application: Oil and gas industry. Journal of Failure Analysis and Prevention, 20(5): 1568-1582. https://doi.org/10.1007/s11668-020-00960-4

[4] Chevalier, F., Laporte, C.Y. (2013). Amélioration des processus de gestion des petits et des moyens projets dans une société d'ingénierie canadienne. Revue Génie Logiciel, 106(5eptember): 20-34.

[5] Vanpoucke, E., Vereecke, A., Wetzels, M. (2014). Developing supplier integration capabilities for sustainable competitive advantage: A dynamic capabilities approach. Journal of Operations Management, 32(7-8): 446-461. https://doi.org/10.1016/j.jom.2014.09.004
[6] Tang, C., Tomlin, B. (2008). The power of flexibility for mitigating supply chain risks. International Journal of Production Economics, 116(1): 12-27. https://doi.org/10.1016/j.ijpe.2008.07.008

[7] Jüttner, U. (2005). Supply chain risk management: Understanding the business requirements from a practitioner perspective. The International Journal of Logistics Management, 16(1): 120-141. https://doi.org/10.1108/09574090510617385

[8] Christopher, M., Peck, H. (2004). Building the resilient supply chain. International Journal of Logistics Management, $15(2)$ : 1-13. http://dx.doi.org/10.1108/09574090410700275

[9] Wagner, S.M., Bode, C. (2008). An empirical examination of supply chain performance along several dimensions of risk. Journal of Business Logistics, 29(1): 307-325. https://doi.org/10.1002/j.21581592.2008.tb00081.x

[10] Kumar, S.K., Tiwari, M.K., Babiceanu, R.F. (2010). Minimisation of supply chain cost with embedded risk using computational intelligence approaches. International Journal of Production Research, 48(13): 3717-3739. https://doi.org/10.1080/00207540902893425

[11] Trkman, P., McCormack, K. (2009). Supply chain risk in turbulent environments - A conceptual model for managing supply chain network risk. International Journal of Production Economics, 119(2): 247-258. https://doi.org/10.1016/j.ijpe.2009.03.002

[12] Chopra, S., Sodhi, M.S. (2004). Supply-chain breakdown. MIT Sloan Management Review, 46(1): 53-61.

[13] Lavastre, O., Gunasekaran, A., Spalanzani, A. (2014). Effect of firm characteristics, supplier relationships and techniques used on supply chain risk management (SCRM): An empirical investigation on French industrial firms. International Journal of Production Research, 52(11): https://doi.org/10.1080/00207543.2013.878057

[14] Manuj, I., Mentzer, J.T. (2008). Global supply chain risk management. Journal of Business Logistics, 29(1): 133155 .

1592.2008.tb00072.x

https://doi.org/10.1002/j.2158-

[15] Ouabouch, L., Amri, M. (2013). Analysing supply chain risk factors: A probability-impact matrix applied to pharmaceutical industry. Journal of Logistics Management, 2(2): 35-40.

[16] Kleindorfer, P.R., Saad, G.H. (2005). Managing disruption risks in supply chains. Production and Operations Management, 14(1): 53-68. https://doi.org/10.1111/j.1937-5956.2005.tb00009.x

[17] Blackhurst, J.V., Scheibe, K.P., Johnson, D.J. (2008). Supplier risk assessment and monitoring for the automotive industry. International Journal of Physical Distribution \& Logistics Management, 38(2): 143-165. https://doi.org/10.1108/09600030810861215

[18] Noon, M., Blyton, P., Morrell, K. (2013). The realities of work: Experiencing work and employment in contemporary society. Macmillan International Higher Education. https://doi.org/10.1111/j.14697998.1992.tb04403.x

[19] Yeboah, J., Ewur, G.D. (2014). The impact of WhatsApp messenger usage on students performance in Tertiary Institutions in Ghana. Journal of Education and Practice, 5(6): 157-164. 
[20] Bolarinwa, O.A. (2015). Principles and methods of validity and reliability testing of questionnaires used in social and health science researches. Nigerian Postgraduate Medical Journal, 22(4): 195-201. https://doi.org/10.4103/1117-1936.173959

[21] Thun, J.H., Hoenig, D. (2011). An empirical analysis of supply chain risk management in the German automotive industry. International Journal of Production Economics, 131(1): 242-249. https://doi.org/10.1016/j.ijpe.2009.10.010

[22] Dani, S. (2009). Predicting and managing supply chain risks. In Supply Chain Risk, pp. 53-66. https://doi.org/10.1007/978-0-387-79934-6_4

[23] Cucchiella, F., Gastaldi, M. (2006). Risk management in supply chain: A real option approach. Journal of Manufacturing Technology Management, 17(6): 700720. https://doi.org/10.1108/17410380610678756

[24] Narasimhan, R., Talluri, S. (2009). Perspectives on risk management in supply chains. Journal of Operations Management, 27(2): 114-118. https://doi.org/10.1016/j.jom.2009.02.001

[25] Blackhurst, J., Dunn, K.S., Craighead, C.W. (2011). An empirically derived framework of global supply resiliency. Journal of Business Logistics, 32(4): 374-391. https://doi.org/10.1111/j.0000-0000.2011.01032.x

[26] Peck, H. (2005). Drivers of supply chain vulnerability: An integrated framework. International Journal of Physical Distribution \& Logistics Management, 35: 210232. https://doi.org/10.1108/09600030510599904

[27] Jüttner, U., Peck, H., Christopher, M. (2003). Supply chain risk management: outlining an agenda for future research. International Journal of Logistics: Research and Applications, 6(4): 197-210. https://doi.org/10.1080/13675560310001627016

[28] Peleg, B., Lee, H.L., Hausman, W.H. (2002). Short-term e-procurement strategies versus long-term contracts. Production and Operations Management, 11(4): 458-479. https://doi.org/10.1111/j.1937-5956.2002.tb00472.x

[29] Tang, C.S. (2006). Robust strategies for mitigating supply chain disruptions. International Journal of Logistics: Research and Applications, 9(1): 33-45. https://doi.org/10.1080/13675560500405584

[30] Agigi, A.F.A., Niemann, W., Kotze, T.G. (2016). Supply chain design approaches for supply chain resilience: A qualitative study of South African fast-moving consumer goods grocery manufacturers. Journal of Transport and Supply Chain Management, 10(1): 1-15. http://hdl.handle.net/2263/60622.

[31] Ochieng, B.E. (2019). Effect of supply chain risk management practices on performance of manufacturing firms in Kenya. Journal of International Business, Innovation and Strategic Management, 2(1): 1-13. http://repository.rongovarsity.ac.ke/handle/123456789/2 032 .

[32] Gunasekaran, A., Subramanian, N., Rahman, S. (2015). Supply chain resilience: Role of complexities and strategies. International Journal of Production Research, 53(22): 6809-6819. https://doi.org/10.1080/00207543.2015.1093667

[33] Darouich, C., Dhiba, Y. (2020). La gestion du risque de la chaine logistique pharmaceutique: Cas des entreprises pharmaceutique marocaines. Revue de Management et Cultures, (5): 125-136. https://doi.org/10.48430/IMIST.PRSM/remac-n5.14912

[34] Kamalahmadi, M., Parast, M.M. (2016). A review of the literature on the principles of enterprise and supply chain resilience: Major findings and directions for future research. International Journal of Production Economics, 171: 116-133. https://doi.org/10.1016/j.ijpe.2015.10.023

[35] Ali, A., Mahfouz, A., Arisha, A. (2017). Analysing supply chain resilience: Integrating the constructs in a concept mapping framework via a systematic literature review. Supply Chain Management: An International Journal, 22(1): 16-39. https://doi.org/10.1108/SCM-062016-0197

[36] Scholten, K., Schilder, S. (2015). The role of collaboration in supply chain resilience. Supply Chain Management: An International Journal, 20(4): 471-484. https://doi.org/10.1108/SCM-11-2014-0386

[37] Liu, Z., Nagurney, A. (2011). Supply chain outsourcing under exchange rate risk and competition. Omega, 39(5): 539-549. https://doi.org/10.1016/j.omega.2010.11.003

[38] Allayannis, G., Ofek, E. (2001). Exchange rate exposure, hedging, and the use of foreign currency derivatives. Journal of International Money and Finance, 20(2): 273296. https://doi.org/10.1016/S0261-5606(00)00050-4 